\title{
Acute effects of smoking on lung airways resistance in normal and bronchitic subjects
}

\author{
M. MCDERMOT T AND M.M. COLLINS \\ From the Pneumoconiosis Research Unit of the Medical Research Council, Llandough Hospital, Penarth, \\ Glamorgan
}

The increase in airways resistance produced when a subject smokes a single cigarette has been investigated by us and others, particularly Nadel and Comroe (1961). These laboratory studies suggested a method of comparing the cumulative effect over years of an inhaled irritant with an individual's acute response.

The consistent epidemiological findings of many workers (Palmer, 1954; Doll and Hill, 1956; Higgins, 1959) that cigarette smokers have an increased incidence of chronic bronchitis and a lower maximum breathing capacity compared with non-smokers support the idea that repeated increases in resistance could, over a period of years, cause detrimental changes.

The laboratory studies were made on very small numbers, and the next logical step was to repeat the work on a larger group of untrained subjects. In 1961 a long-term follow-up of bronchitic symptoms and ventilatory capacity in 272 clerical officers at the Post Office Savings Bank in London was started by Dr. C. M. Fletcher and his colleagues at the Postgraduate Medical School of London. They allowed us to use a group of 60 of these men for our studies, and provided us with full information on symptoms and ventilatory capacity and the use of their survey organization.

The 60 men were volunteers from among cigarette smokers only, and were selected on the basis of replies to a questionnaire self-administered in 1961 ; approximately half were 'normal' and half were 'bronchitic'. The 'bronchitics' admitted to chronic expectoration and a recent chest illness, whereas the 'normals' had denied these symptoms.

Our object was to compare in the two groups the change of airways resistance after smoking a single cigarette, the repeatability of resistance measurements, and the repeatability of the change produced by smoking.

The men were later divided for analysis into four groups, based on replies to a fuller question- naire asked in July 1961 (Appendix 1), and on the average of five measurements of the volume of early morning sputum (Elmes, Dutton, andFletcher, 1959) at separate times over a period of $Z$ two years (1961-62), spanning both summer and winter.

The numbering and order of the questions in Appendix 1 is not in numerical sequence but is $\overrightarrow{-}$ the same as that of the Medical Research Councilo Bronchitis Questionnaire. Only a selection of questions from the M.R.C. questionnaire was used. and the same headings (Cough, Phlegm, etc.) and question numbers have been kept to simplify com parison with results on other populations.

\section{SUBJECTS}

The groups were as follows:

GROUP 0 (20 men) The subjects said that they dido not 'bring up phlegm on most days for as much as three months each year' (Q. 10), and they pro-O duced no early morning sputum.

GROUP 1 (12 men) (a) The subjects said that they 'usually brought up phlegm first thing in the morn ing in the winter' (Q. 6), or they 'brought ups phlegm during the day or at night in the winter (Q. 8), and that this lasted for more than three months each year (Q. 10). They produced no early morning sputum. (b) The subjects said 'Yes' to Q. 6 or Q. 8 and Q. 10 as in $(a)$, and produced some early morning sputum, but this was less than $2 \mathrm{ml}$. in quantity. (c) The subjects said 'No' ton Q. 10 but produced some early morning sputum ${ }_{0}^{\omega}$ which was less than $2 \mathrm{ml}$. in quantity.

Group 2A (13 men) The subjects said 'Yes' tơ⿱ $\mathrm{Q} .6$ and $\mathrm{Q} .8$ and $\mathrm{Q}$. 10 and $/$ or produced at least $2 \mathrm{ml}$. sputum. In addition each subject had not more than one symptom from the following:O

Question 12b, c At least 'one period o⿱ increased cough and phlegm lasting thre $\mathbb{\mathscr { D }}$ weeks or more'. 
Question 14a 'Shortness of breath when hurrying on the level or walking up a slight hill'.

Question 50a The weather (such as fog or cold) produced shortness of breath.

Question 21a During the past three years a chest illness kept the man off work for as much as a week, and during the illness more phlegm than usual was produced.

Question 51 'A chest cold lasting at least three weeks or more each winter'.

GROUP 2B (15 men) The subjects said 'Yes' to $\mathrm{Q}$. 6 and $\mathrm{Q}$. 8 and $\mathrm{Q}$. 10 and/or produced at least $2 \mathrm{ml}$. sputum and also had more than one symptom from among those listed for group 2a.

Groups 0 and 1 together have been taken as 'normals', and groups $2 \mathrm{a}$ and $2 \mathrm{~b}$ together as 'bronchitics'. This definition of bronchitic is at a very slight level of abnormality; all the men were relatively fit and working full time. The mean forced expiratory volume in one second of the bronchitic group was 2.91 . compared with 3.31 . for the normals. Both groups covered the same age range of 35 to 60 years with a similar mean age of 46 years.

\section{PI.AN OF THE EXPERIMENT}

Each man was seen for 20 minutes once a week, three weeks running, at the same time on the same day if possible, to reduce variation due to daily and weekly cyclical changes in airways resistance. The men were asked not to smoke for at least one and a half hours before each experiment, so that any temporary increase in airways resistance produced by previous cigarettes would not modify the results. On each occasion simultaneous measurements of airways resistance and thoracic gas volume were made using a body plethysmograph (DuBois, Botelho, and Comroe, 1956).

With this technique the resistance is recorded while the subject pants shallowly one to two times a second; the flow rate at which the resistance is measured is $0.5 \mathrm{l} . / \mathrm{sec}$., and the volume of air moved is about $200 \mathrm{ml}$. Hence it is possible to record airways resistance at a fixed flow rate at any lung volume from full inspiration to full expiration. The diameter of the airways and therefore the resistance to airflow will vary with the degree of inflation of the lungs; resistance is minimal at full inspiration and maximal at full expiration (Briscoe and DuBois, 1958). The relation is very approximately ${ }_{R}^{1}=a+b V, a$ and $b$ being constants for each man, provided $V$ is not too close to full inspiration or expiration. The constants do not change with the small degree of bronchospasm, such as is caused by cigarette smoking, but they will be altered if very large increases in airways resistance are produced with inhaled bronchoconstrictors such as histamine. It is impossible in untrained subjects to control the degree of inflation of the lungs at which the resistance is measured, so that, in an experiment involving repeat measurements over several weeks on each man, some correction must be applied. We obtained for each man, once only, the relation between resistance and lung volume, calculated the constant $b$, and corrected the individual airways resistance measurements made at different times to the mean thoracic gas volume for each man averaged over the whole experiment. For the small variations of volume and resistance with which we are concerned this is a sufficiently good approximation. Resistance was measured during the inspiratory phase of panting, and the units used are $\mathrm{cm} . \mathrm{H}_{2} \mathrm{O} / \mathrm{l}$. $/ \mathrm{sec}$.

After the resistance measurement had been taken during the first week, the subjects smoked a cigarette while sitting reading or chatting to one of the investigators, so that the method of smoking was as near normal as possible. Another observer recorded the period of time the cigarette was alight, the length of stub, and whether the smoke was inhaled deeply, moderately or not at all. These criteria are similar to those used by the Tobacco Manufacturers' Standing Committee (1962). The depth of inhalation was judged on the colour and density of the exhaled smoke, and the man's own views about how deeply he inhaled were also noted.

The measurements made during the first week were regarded as practice for both the subjects and the observers and were not analysed. If a subject could not come again, because of holidays or illness, or was completely incapable of learning how to do the test, or was an ex-smoker, he was replaced by another volunteer. About a dozen men had to be replaced, four because they were unable to do the test.

In the following two weeks (referred to from now on as the 1st and 2nd weeks) airways resistance was measured either before and after the subject had smoked a cigarette, or before and after a control period of approximately the same length of time. The technique of smoking was recorded as before. Whether the subject smoked or was a control depended on to which of the four experimental groups he had been randomly allocated ; 20 men smoked both weeks, 20 men smoked neither week, 10 men smoked the 1 st week and not the 2 nd, and 10 men smoked the 2 nd week but not the 1 st. The men were allocated to these groups irrespective of whether they were normal or bronchitic subjects.

\section{RESULTS}

ANALYSIS OF SMOKING TECHNIQUE In both Table I and Table II there is no obvious difference between the way in which the bronchitics and the normals smoked a cigarette. These results are similar to those published by the Tobacco Manu- 
T A B LE I

\begin{tabular}{llll|l|l}
\hline \multicolumn{2}{c|}{ Degree of Inhalation } & Normal & Bronchitic \\
\hline None & $\ldots$ & $\ldots$ & $\ldots$ & $19 \%(6)$ & $14 \%(4)$ \\
Medium & $\ldots$ & $\ldots$ & $\ldots$ & $56 \%(18)$ & $64 \%(18)$ \\
Deep &. & $\ldots$ &. & $25 \%(8)$ & $21 \%(6)$ \\
\hline
\end{tabular}

T A B LE II

\begin{tabular}{|c|c|c|}
\hline & Normal & Bronchitic \\
\hline $\begin{array}{l}\text { Time taken to smoke a } \\
\begin{array}{l}\text { cigarette (min.) } \\
\text { Length of stub (in.) }\end{array} \\
\text { No. of puffs }\end{array}$ & $\begin{array}{c}8 \cdot 8 \\
0 \cdot 9 \\
14\end{array}$ & $\begin{array}{l}8.4 \\
1 \cdot 0 \\
13\end{array}$ \\
\hline
\end{tabular}

facturers, and, like them, we found there was good agreement between the observer's and the subject's assessment of the degree to which the smoke was inhaled.

The weight of tobacco smoked by each man per week was obtained from the results of a questionnaire asked at the time of the investigation, and it appears to be related to a man's inhaling habits (Table III), but the number of non-inhalers and

TAB LE III

\begin{tabular}{|c|c|c|c|c|}
\hline \multirow{2}{*}{\multicolumn{3}{|c|}{ Degree of Inhalation }} & \multicolumn{2}{|c|}{ Wt. of Tobacco Smoked par Week (g.) } \\
\hline & & & Normal & Bronchitic \\
\hline $\begin{array}{l}\text { None } \\
\text { Medium } \\
\text { Deep }\end{array}$ & $\begin{array}{l}\cdots \\
\cdots \\
\cdots\end{array}$ & $\begin{array}{l}\ldots \\
\cdots \\
\cdots\end{array}$ & $\begin{array}{r}73 \\
105 \\
119\end{array}$ & $\begin{array}{r}98 \\
106 \\
140\end{array}$ \\
\hline \multicolumn{3}{|c|}{ Mean } & 103 & 112 \\
\hline
\end{tabular}

deep inhalers is too small to draw a definite conclusion.

DISTRIBUTION OF AIRWAYS RESISTANCE Figure 1 shows the distribution of airways resistance separately for the two groups. These differ significantly at the $1 \%$ level. The mean resistance of the bronchitics is $1.16 \mathrm{~cm} . \mathrm{H}_{2} \mathrm{O} / 1$. $/ \mathrm{sec}$. and that of the normals is $0.91 \mathrm{~cm} . \mathrm{H}_{2} \mathrm{O} / 1$. $/ \mathrm{sec}$. There is much greater scatter in the bronchitic than in the normal group (the ratio of the standard deviations is $1 \cdot 8: 1)$. The mean resistance for group 0 is 0.87 $\mathrm{cm} . \mathrm{H}_{2} \mathrm{O} / 1$. / sec., for group 1 it is 0.99 , for group $2 \mathrm{a}$ it is $1 \cdot 13$, and for group $2 \mathrm{~b}$ it is $1.19 \mathrm{~cm} \cdot \mathrm{H}_{2} \mathrm{O} /$ 1./sec., so that an increase in symptoms is accompanied by an increase in airways resistance. These resistances appear low, and this is because each man was allowed to do the test at the thoracic gas

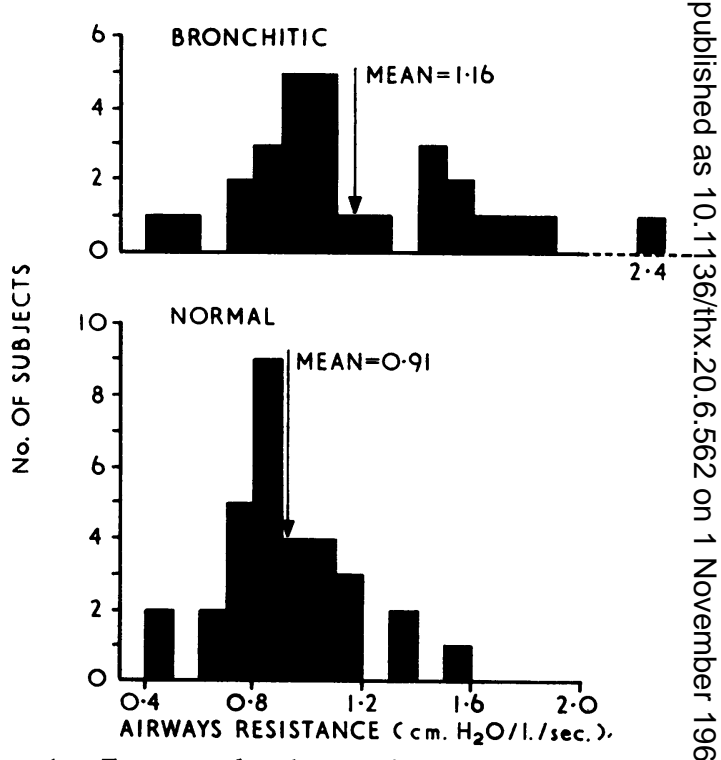

FIG. 1. Frequency distribution of airways resistance befores smoking in normal and bronchitic groups. Each reading is the mean of the observations in the 1 st and 2 nd weeks.

volume of his own choice, which was generally⿳亠े口 about 5 litres. This is sufficiently close to full inspiration for resistance to be almost at its minimum.

WEEK TO WEEK REPEATABILITY OF AIRWAYS RESIST ANCE Figure 2 shows separately for the normals and bronchitics the resistance in the 2nd weeko plotted against the value for the 1 st week. The standard error of the mean of four observationso on the normals is $11.4 \%$, and it is $15.7 \%$ for the 3 . bronchitics, a difference in repeatability which is significant at the $1 \%$ level. These are higher than the value of $7 \%$ which we obtained in our labora-o tory work. The reason for the difference of the standard error in the normals and the laboratoryo subjects might be that the good repeatability of airways resistance is an index of complete absence of respiratory symptoms, since the labora- -0 tory staff probably had even fewer symptoms than N the normals in the Post Office Savings Bank. Thiso conclusion is consistent with the significant differ-o ence between the normals and the bronchitics. However, a more probable explanation is the increased technical difficulties of obtaining results on untrained subjects. DuBois et al. (1956), in their paper on the body plethysmograph, obtained a standard error of the mean of approximately $\underset{\varrho}{\mathbb{\Phi}}$ $18 \%$ in a group of 10 subjects measured in the
laboratory on two different days. 


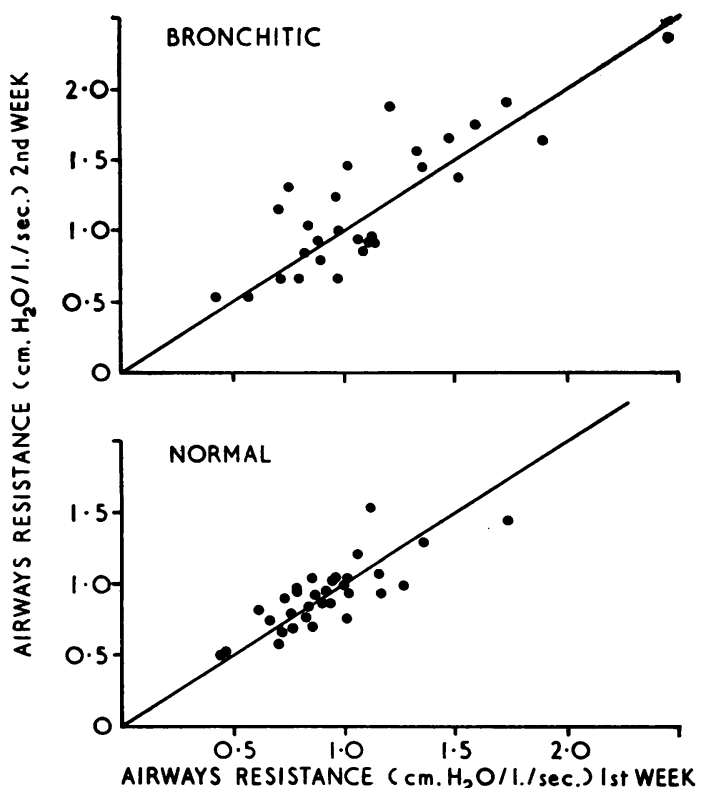

FIG. 2. Repeatability of airways resistance.

DISTRIBUTION OF AIRWAYS RESISTANCE CHANGE WITH SMOKING The distributions of the change in resistance produced by smoking a single cigarette are shown on the right-hand side of Fig. 3, and on

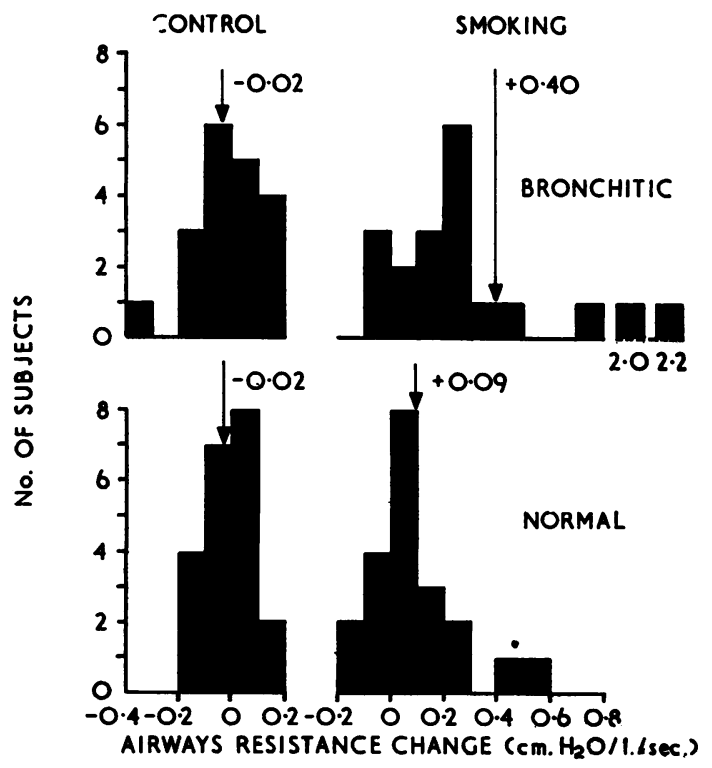

FIG. 3. Frequency distribution of change in airways resistance produced by smoking. the left are the distributions of the change in the controls who did not smoke. For those subjects who smoked or were non-smoking controls both weeks, the results have been averaged and treated as a single observation. The change for the controls in both normals and bronchitics is similar, with a mean of $-0.02 \mathrm{~cm} . \mathrm{H}_{2} \mathrm{O} / 1$. $/ \mathrm{sec}$. The response of the bronchitics to smoking a cigarette is clearly greater than that of the normals, though both changes are significant. The mean increase for the bronchitics is $+0.4 \mathrm{~cm} . \mathrm{H}_{2} \mathrm{O} / \mathrm{l}$. $/ \mathrm{sec}$., compared with an increase of +0.09 for the normals, a difference which is significant at the $5 \%$ level. In the normals, group 0 changed by +0.11 and group 1 by $+0.04 \mathrm{~cm}$. $\mathrm{H}_{2} \mathrm{O} / 1$. $/ \mathrm{sec}$. In the bronchitics, group $2 \mathrm{a}$ changed by $+0 \cdot 17$, and group $2 \mathrm{~b}$ by $+0.65 \mathrm{~cm} . \mathrm{H}_{2} \mathrm{O} / 1$. $/ \mathrm{sec}$.

REPEATABILITY OF AIRWAYS RESISTANCE CHANGE WITH SMOKING Figure 4 shows the change after smoking in the 2nd week, plotted against the change after smoking in the 1st week. The bronchitics, of whom there were nine, vary more than the 11 normals in their response to smoking a cigarette. This difference in repeatability was almost significant at the $5 \%$ level $(P \simeq 0.06)$. Unfortunately, by chance those bronchitics who showed the largest increases in resistance after smoking did not occur in the group which smoked on both occasions.

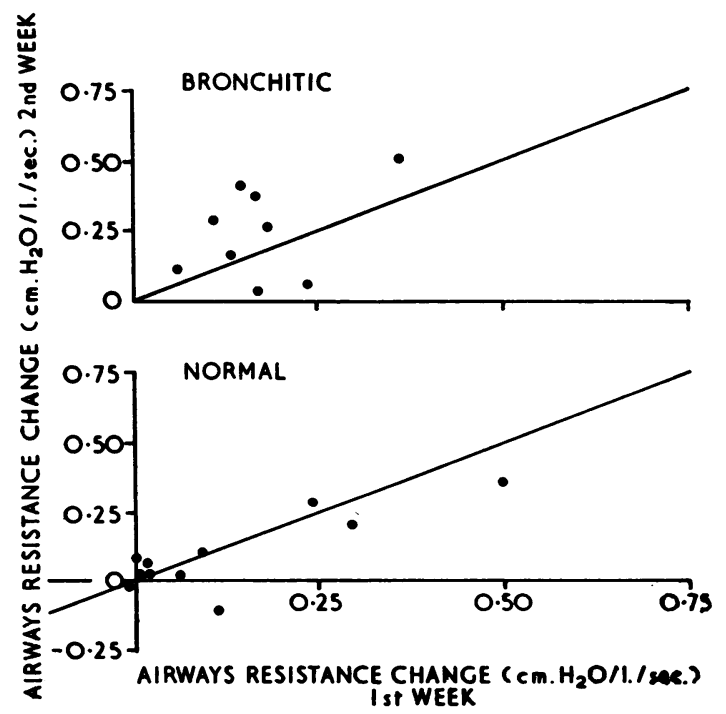

FIG. 4. Repeatability of the change in airways resistance produced by smoking. 
RELATION BETWEEN DEGREE OF INHALATION AND AIRWAYS RESISTANCE CHANGE Figure 5 shows the resistance change after smoking a single cigarette, divided into the three inhaling categories, none, medium, and deep. There appears to be a relation between the depth of inhalation of the smoke and the resistance change produced in the bronchitics but not in the normals: this observation is not statistically significant on these small numbers. There is no relation for either the bronchitic or the normal subjects between the airways resistance before smoking and inhaling habits.

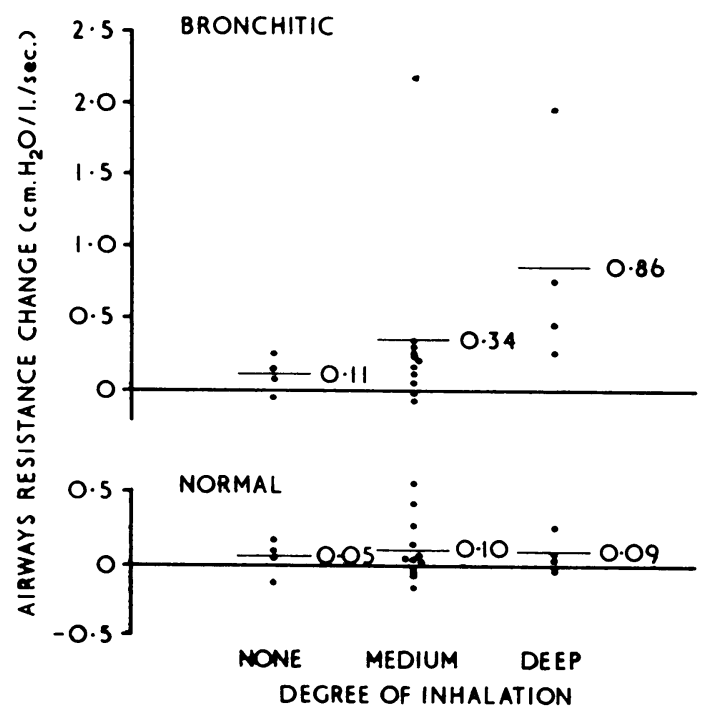

FIG. 5. Effect of the depth of inhalation of cigarette smoke on airways resistance.

A separate analysis of the data was made with the 60 men divided into light smokers $(<105 \mathrm{~g}$. tobacco/week) and heavy smokers ( $\geqslant 105 \mathrm{~g} . /$ week). The mean airways resistance before smoking of the 40 subjects who smoked at least once was $1.05 \mathrm{~cm} . \mathrm{H}_{2} \mathrm{O} / 1$./ $\mathrm{sec}$. for the light smokers and 1.04 for the heavy smokers. The respective changes after smoking were +0.27 and $+0.21 \mathrm{~cm} . \mathrm{H}_{2} \mathrm{O} / 1$./ sec. For the whole group of 60 men the airways resistance of the light smokers was 1.02 and for the heavy smokers it was $1.04 \mathrm{~cm} . \mathrm{H}_{2} \mathrm{O} / \mathrm{l} . / \mathrm{sec}$., and there was no difference in the mean sputum volume of the groups.

The questionnaire from which the men were classified for analysis into bronchitics or normals also included answers to questions about cough, breathlessness, effect of weather, chest colds, chest illnesses, and a family history of asthma or hay fever (Appendix 1).
The questions used in the analysis were:

Question 5 Do you cough either first thing in $\frac{\bar{c}}{2}$ the morning in winter, or during the day or at $\mathbb{Q}$ night in winter on most days for as much as three months each year?

Question 10 Do you usually bring up phlegm. first thing in the morning in the winter or during $\overrightarrow{\vec{H}}$ the day, or at night in winter on most days for $\omega$ as much as three months each year?

Question $14 b$ Do you get short of breath walking with other people at an ordinary pace on the level?

Question 21 During the past three years have you had any chest illness which has kept you off 으 work for as much as a week ?

Question 50 Does the weather (such as fog or $\bar{z}$ cold) affect your chest?

Question 51 Do you have a chest cold lasting three weeks or more each winter?

Question 52 Have you ever had asthma?

Question 53 Have you ever had hay fever?

Question 54 Did your mother or father ever of have hay fever or asthma?

Question 55 Have any of your brothers or sisters ever had hay fever or asthma?

In theory each man could have had one of $2^{10}$ possible combinations of these 10 symptoms. However, the chance of a man having any one symptom is not independent of other symptoms which he may have; and Appendix 2 shows the combinations of symptoms which occurred in the sample, of which there were 24 out of the maximum of 60 (i.e., the number of subjects). A similar approach on a much larger group could give a great deal of information about which complexes of symptoms are most likely to exist, and which 3 . symptoms are useful, and which are redundant in $\delta$ categorizing a man. For example, in this group, of $₹$ the 35 men who answered 'yes' to Q. 5, only five o did not also answer 'yes' to Q. 10, so one or other of these questions could probably be usefully omitted from future questionnaires. Fletcher, Elmes, Fairbairn, and Wood (1959), in a study on $\Omega$ the diagnosis of chronic bronchitis, have pre- N viously noted that practically all men who answer 'yes' to Q. 5 also give a positive answer to Q. 10.

This form of breakdown into groups of symptoms can also be used to study the relation between objective physiological measurements and symptoms. It is reasonable to speculate that if a man produces a large quantity of sputum, this, by mechanically blocking the airways, would cause an increase in airways resistance. In the whole group of 60 men, as expected, there was a significant correlation of $+0.50(<0.1 \%$ level $)$ between 
the airways resistance and sputum volume. However, within each symptom complex there was a negligible correlation. This means that, although subjects who produce a large amount of sputum tend to have a high airways resistance, there is probably no direct causal relationship, and for a group of men all with the same symptoms, there will be no relationship or the reverse one.

The number of subjects with similar groups of symptoms is very small, and possibly a larger study would give different findings, but this is an interesting result.

\section{DISCUSSION}

The relation between airways resistance and thoracic gas volume was the same for all four groups, $0,1,2 \mathrm{a}$, and $2 \mathrm{~b}$. The difficulty of comparing the mean resistances which we obtained with those of other workers is illustrated by using the resistance/volume relationship to estimate what the resistance would have been if we had made the measurements at a different thoracic gas volume, and this is shown in Table IV.

TABLE IV

\begin{tabular}{|c|c|c|c|c|}
\hline & \multicolumn{2}{|c|}{ Measured } & \multicolumn{2}{|c|}{ Estimated } \\
\hline & $\begin{array}{c}\text { Resistance } \\
\left(\mathrm{cm} . \mathrm{H}_{2} \mathrm{O} /\right. \\
1 . / \mathrm{sec} .)\end{array}$ & $\begin{array}{c}\text { Thoracic } \\
\text { Gas } \\
\text { Volume (1.) }\end{array}$ & $\begin{array}{c}\text { Resistance } \\
\text { at } \\
3.01 \text {. }\end{array}$ & $\begin{array}{c}\text { Resistance } \\
\text { at } \\
4.01\end{array}$ \\
\hline $\begin{array}{l}\text { Normal } \\
\text { Bronchitic }\end{array}$ & $\begin{array}{l}0.91 \\
1.16\end{array}$ & $\begin{array}{l}4 \cdot 81 \\
4 \cdot 58\end{array}$ & $\begin{array}{l}2.00 \\
2.94\end{array}$ & $\begin{array}{l}1 \cdot 21 \\
1.49\end{array}$ \\
\hline
\end{tabular}

Similarly, the numerical magnitude of the change in resistance with smoking will also depend on the volume of air in the lungs. At 4 litres the changes would have been approximately twice as large as at the 4.6 and 4.8 litres at which the measurements were made. This does not necessarily mean that greater sensitivity would be obtained at a lower thoracic gas volume, as the variability of the airways resistance would also be greater.

The pathological basis for the increase in airways resistance in the bronchitic subjects compared with the normals is not known. Although the bronchitic group have by definition an increase in bronchial secretions, the finding that there is probably no direct relation between airways resistance and sputum volume makes this an unlikely explanation. Another possibility is that it is due to reversible bronchoconstriction, and had there been sufficient time, this could have been tested by the use of an inhaled bronchodilator aerosol. The great variability from week to week in the bronchitics suggests that at least some of the increase was due to reversible narrowing of the airways.

The increase in resistance produced by smoking a cigarette showed no relation to the depth to which the smoke was inhaled in the men without respiratory symptoms, and this agrees with the findings of Zamel, Youssef, and Prime (1963). Even if the smoke is not inhaled, a large fraction will travel into the upper airways, where it can cause a reflex bronchoconstriction similar to that produced by chemically inert particles (Nadel and Comroe, 1961), but even then one would expect a greater response to a greater stimulus. The results on the bronchitics suggest there might be a correlation between the depth of inhalation of the smoke and the response. Perhaps there are two separate mechanisms-in the men without symptoms there is a pure bronchoconstriction caused by a reflex response in the upper airways where the smoke reaches even if it is not inhaled; and in the bronchitics there is equally this bronchoconstriction but it is accompanied by vascular congestion and mucosal oedema if the smoke reaches the lower airways.

This study shows that even in subjects with very minor symptoms of chronic bronchitis, there is an increase in airways resistance, which is also more variable. Cigarette smoke is an inhaled irritant for which it is reasonably easy to estimate the dose over years and also to measure the acute response. It should be possible to find the acute response of a large group of smokers without respiratory symptoms and then follow the same men for many years, by questionnaire and physiological tests, to find whether those who respond most are the subjects who finally develop chronic bronchitis and emphysema. It is also important to know whether a subject who is sensitive to inhaled cigarette smoke responds to other inhaled irritants such as coal dust, sulphur dioxide, oxides of nitrogen, etc.

The use of airways resistance measurements as an index of acute response may not be the right measure, but it is an index which differentiates between people with great sensitivity; and longterm studies of this and other physiological variables, combined with studies of the acute effects, should eventually provide the solution to the apparent association between chronic bronchitis and cigarette smoking.

\section{SUMMARY}

A study of a group of 60 men, who were Post Office workers in London aged 35 to 60 years, 
showed that the airways resistance of 'bronchitics' (including subjects with only minimal abnormality) was higher than in those with no respiratory symptoms, and it varied more from day to day. Bronchitics showed a larger increase in resistance than normals after smoking a cigarette, and this change was more variable.

The method by which a man smoked a cigarette was the same for the bronchitics as for the normals, and, although the numbers were too small to draw a definite conclusion, it appeared probable that the greater the weekly consumption of tobacco, the deeper the smoke was inhaled.

The average airways resistance was similar for both light and heavy smokers, though the light smokers showed a slightly greater increase of resistance after smoking a cigarette than the heavy smokers.

There is an apparent statistical association between the volume of sputum produced by a subject and his airways resistance, but this association is probably through the effect of symptoms (other than sputum volume) and is not a direct one.

This work was made possible only by the very considerable help of Dr. C. M. Fletcher and of his colleagues, particularly Dr. C. Tinker of the Postgraduate Medical School of London.
We should like to thank the staff of the Post Office Savings Bank who volunteered as subjects, and Mr. J. Hansford, also from the Post Office Savings Bank, who helped with the organization.

We are also grateful to Mr. G. W. Cook of the Pneumoconiosis Research Unit for the statistical design and analysis, and to Miss R. A. Hart, Miss V. Thick. and Mr. R. B. John for technical assistance.

\section{REFERENCES}

Briscoe, W. A., and DuBois, A. B. (1958). The relationship between airway resistance, airway conductance and lung volume in subjects of different age and body size. $J$. clin. Invest $, 37,1279$.

Doll, R., and Hill, A. B. (1956). Lung cancer and other causes of death in relation to smoking. A second report on the mortality of British doctors Brit med. J. 2, 1071.

DuBois, A. B., Botelho, S. Y., and Comroe, J. H., Jr. (1956). A new method for measuring airway resistance in man using a body plethysmograph: values in normal subjects and in patients with respiratory disease. J. clin. Invest., 35, 327.

Elmes, P. C., Dutton, A. A. C., and Fletcher, C. M. (1959). Sputum examination and the investigation of 'chronic bronchitis'. Lancet, 1, 1241 .

Fletcher, C. M., Elmes, P. C. Fairbairn, A. S., and Wood, C. H. (1959). The significance of respiratory symptoms and the diagnosis of chronic bronchitis in a working population. Brit. med.J., $2,257$.

Higgins, I. T. T. (1959). Tobacco smoking, respiratory symptoms, and ventilatory capacity. Studies in random samples of the population. Ibid., 1, 325 .

Nadel, J. A., and Comroe, J. H., Jr. (1961). Acute effects of inhalation of cigarette smoke on airway conductance. J. appl. Physiol., 16, 713

Palmer, K. N. V. (1954). The role of smoking in bronchitis. Brit. med. J., 1, 1473

Tobacco Manufacturers' Standing Committee (1962). Statistics of Smoking in the United Kingdom, edited by G. F. Todd, 3rd edition. (Research Papers, No. 1.) London.

Zamel, N., Youssef, H. H., and Prime, F. J. (1963). Airway resistance and peak expiratory flow-rate in smokers and non-smokers. Lancet, 1, 1237.

\section{APPENDIX 1}

QUESTIONNAIRE. JULY 1961

\section{COUGH}

Do you usually cough first thing in the morning in the winter?

Do you usually cough during the day or at night in the winter?

If 'Yes' to 1 or 3 :

Do you cough like this on most days for as much as three months each year?

\section{PHLEGM}

Do you usually bring up any phlegm from your chest first thing in the morning in the winter?

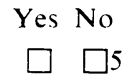

Yes No

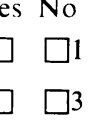

Do you bring up any phlegm from your chest during the day or at night in the winter?

If 'Yes' to 6 or 8 :

Do you bring up phlegm like this on most days for as much as three months each year?

In the past three years, (No $\square 12 \mathrm{a}$ have you had a period of increased cough and phlegm lasting for three weeks or more?
Yes No $\square 10$ Only one Yes period Two or more $\square 12 \mathrm{c}$ periods 
QUESTIONNAIRE, JULY 1961 (contd.)

\section{BREATHLESSNESS}

Are you ever troubled by shortness of breath when hurrying on the level or walking up a slight hill ?

$$
\text { If 'Yes' to 14a: }
$$

Do you get short of breath walking with other people at an ordinary pace on the level ?

If 'Yes' to $14 \mathrm{~b}$ :

Do you have to stop for breath when walking at your own pace on the level?

\section{EFFECT OF WEATHER}

Does the weather (such as fog or cold) affect your chest?

If 'Yes' to 50:

Does it make you (more) short of breath?
Yes No

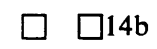

Yes No

$\square 14 \mathrm{a}$

Yes No

$\square 50$

Yes No

$\square 50 \mathrm{a}$

\section{CHEST ILLNESSES}

During the past three years have you had any chest illness which has kept you off work for as much as a week ?

If 'Yes' to 21 :

Did you bring up more phlegm than usual in any of these illnesses?

Do you have a chest cold lasting three weeks or more each winter?

Have you ever had asthma?

Yes No

Yes No

Have you ever had hay fever?

Yes No

FAMILY AND SOCIAL

Did your mother or father ever have hay fever or asthma ?

Yes No

Have any of your brothers or sisters ever had hay fever or asthma?
Yes No $\square 55$

APPENDIX 2

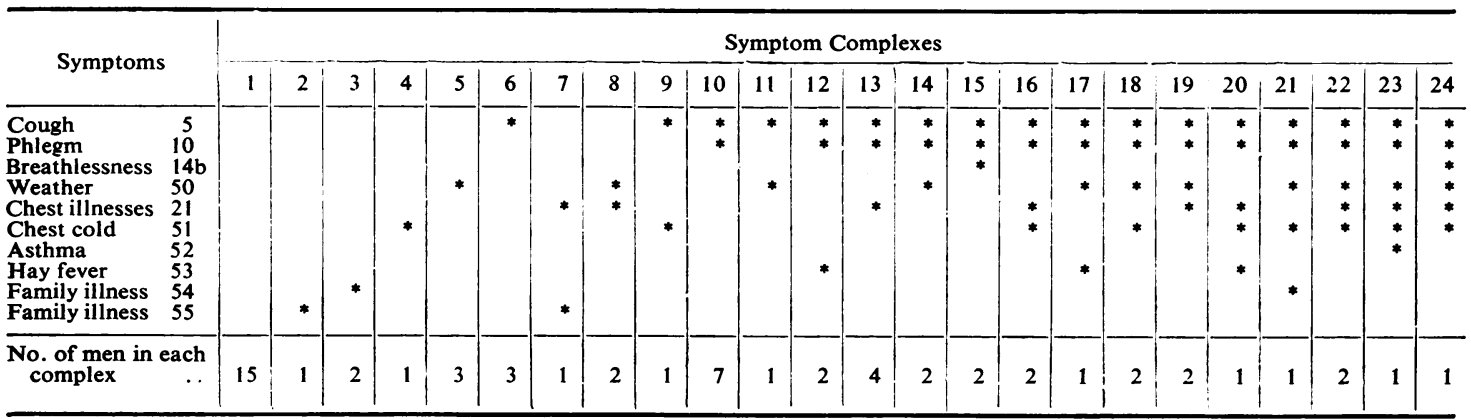

